\title{
Resenha
}

SOUTY, Jérôme. Pierre Fatumbi Verger: do olhar livre ao conbecimento iniciático. São Paulo, Editora Terceiro Nome, 2011, 446 pp. Tradução de Michel Colin.

\section{Um homem plural: sobre a "obra-vida" de Pierre Verger}

\author{
Clara Flaksman \\ Universidade Federal do Rio de Janeiro, Rio de Janeiro, RJ, Brasil \\ claraflaksman@terra.com.br
}

Pierre Verger dizia que virou etnógrafo "por acaso": "se deixou guiar (...) pelo acaso e pelos encontros" (:19). Porém, todos aqueles que conhecem um pouco do funcionamento das religióes de matriz africana no Brasil sabem que, em sua lógica particular, não existe algo como o acaso. As decisões que definem o destino de alguém não são tomadas exclusivamente pela pessoa - ao menos pela pessoa como nós, ocidentais, a concebemos. No candomblé, o destino (odu) é determinado também pela vontade do(s) orixá(s) que habita(m) a cabeça da pessoa; assim, não é de se estranhar que alguém venha a fazer o santo contra a vontade, ou mesmo que seja levado a assumir um cargo dentro de um terreiro sem assim o desejar.

A vida de Verger, como nos conta Jerome Souty em seu livro Pierre Fatumbi Verger: do olhar livre ao conhecimento iniciático, parece seguir à risca esse corolário. Recheada de contradiçôes, ele parece ter vivido muitas vidas em uma: ao mesmo tempo em que cresceu em uma família burguesa, passou a vida com poucas posses; embora um francês cartesiano que lamentava não ter crença alguma, iniciou-se em três vertentes das religióes africanas; decidido a cometer suicídio aos quarenta anos, viveu quase cem. Ele morre enquanto Pierre Verger e renasce como Fatumbi; posteriormente, volta a ser Pierre Verger e termina a vida como Pierre Fatumbi Verger, nome que escolheu para a sua lápide, como se a unidade entre 
as personas que o habitavam pudessem enfim encontrar a paz (:381). Na formulação de Souty, "A alteridade tornou-se pouco a pouco parte constitutiva de sua identidade. Verger tornou-se outro, continuando a ser ele mesmo" (:381). O que parecia uma busca identitária ao longo de toda a sua vida, revela-se, no livro de Souty, como uma existência múltipla. De maneira engenhosa, o autor mostra paulatinamente a coerência que havia por trás do aparente paradoxo da vida de Verger. Ele era, nas palavras de Souty, um "intercessor" (:387), uma pessoa entre duas culturas, cujo encontro com o outro tem a capacidade de trazer à tona a real personalidade do sujeito. E, no caso de Verger, "querer ser outro significa, em primeiro lugar, querer ser negro" (:254), o que faz com que sua busca da África se confunda "com uma busca identitária" (:206).

Não é de estranhar, portanto, que ele tenha encontrado acolhimento no modelo de existência iorubá (cuja multiplicidade constitutiva não é paradoxal - :389), já que, como nos conta Souty, "para os iorubás, o indivíduo é um ser compósito, feito de uma pluralidade de elementos" (:390). Além disso, “a iniciação consiste também no acesso a um melhor conhecimento de si mesmo" (:342). Inicia-se, portanto, para se tornar aquilo que na verdade se é. Esse duplo pertencimento, no caso de Verger, serve como ferramenta de análise antropológica, neste contexto particular no qual a iniciação serve ao mesmo tempo como elemento de afirmação da identidade e como método de pesquisa. Seus estudos são, notavelmente, feitos a partir "de dentro" e também "de fora”, termos muito utilizados para se referir à relação que os pesquisadores de candomblé mantêm com a religião. Verger era "de dentro", pois iniciou-se; mas também era "de fora", pois nunca se livrou do modo europeu de pensar. Lamentava a sua falta de crença e mais ainda o fato de nunca ter entrado em transe. Porém, a escolha (ainda que fruto do "acaso") de Verger pelas religiōes de matriz africana condiz também com a sua falta de crença, já que estas se caracterizam primeiramente pelo ato - Souty conta que certa vez, ao ser perguntado se acreditava no candomblé, Verger respondeu: "vivo como se" (:362). Assim, nas religiōes de matriz africana - entre as quais um duplo pertencimento não caracteriza um problema -, Verger pôde encontrar a identidade que, aparentemente, sempre buscou: um "indivíduo em posição de entremeio" (:387), um “homem plural” (:388). Ao final do livro, Souty chama a atenção para o fato de que "as ciências humanas (...) parecem carecer de ferramentas para analisar esse grupo heterogêneo que reúne indivíduos em interface” (:387). 
O livro de Souty, versão revista e adaptada de sua tese de doutorado defendida em 2005, na Ehess, em Paris, faz jus à complexidade e à multiplicidade da vida e da obra de Verger. Sua minuciosa pesquisa incluiu um amplo levantamento bibliográfico, tanto dos escritos acadêmicos de Verger quanto de correspondências trocadas por ele ao longo da vida, além do seu grande arquivo fotográfico (algumas destas fotografias ilustram o livro, espalhadas de maneira engenhosa ao longo dos capítulos, o que permite que o leitor de certa maneira visualize aquilo que está sendo dito) e de entrevistas feitas tanto em Paris quanto em Salvador ao longo dos anos de 1993 e 1994. Porém, chama a atenção o conhecimento de Souty sobre o próprio tema das religiōes de matriz africana no Brasil, fruto de pesquisas feitas em Salvador e no Rio de Janeiro. Esse é um dos fatores que faz com que um livro escrito sobre um autor sobre quem tanto já se escreveu traga um olhar (aqui no sentido empregado por Souty, como metáfora para uma maneira mais ampla de ver o mundo) novo e instigante.

A primeira parte do livro trata do método de pesquisa de Verger, tanto na fotografia quanto na etnografia, traçando um paralelo que se estende por todo o livro. O "olhar", ou melhor, a maneira de olhar de Verger era muito próxima em ambos os casos. Na fotografia, sua opção por uma câmera rolleiflex traduz esse olhar: trata-se de uma câmera silenciosa, que náo é apontada diretamente para o sujeito (:57), o que permitia uma relaçáo de igualdade entre o fotógrafo e aquele que é fotografado (:58). Podemos perceber este mesmo olhar em suas pesquisas etnográficas, empático e não intrusivo. Verger adiantou vários dos temas que hoje são quase regra no método etnográfico da antropologia pós-colonial, a saber, a não existência de hipótese previamente concebida, escrita descritiva mais que explicativa, preocupação com a leitura nativa, respeito ao que é secreto. Devereux, por exemplo, afirma que a informação obtida por Verger é fruto da "experiência compartilhada" (:72).

A todo momento, Souty deixa claro que o que parecia displicência da parte de Verger (ou "acaso") era, na verdade, um método próprio de organização (:183). Ao se recusar a seguir o roteiro pré-estabelecido de um pesquisador, alcançando metas ou respeitando uma temporalidade imposta, Verger construiu, respeitando seus princípios, uma carreira acadêmica profícua. Seja fotografando o que nunca havia sido fotografado, ou mesmo debruçando-se sobre os arquivos da escravidão depois de tantos anos de pesquisa 
etnográfica, a sensação que temos ao ler o livro de Souty é que Verger sempre fez o que quis: "o único homem livre que eu conheço", como se referiu a ele Théodore Monod (:45).

A estrutura do livro é dividida em pequenas seçôes, cada uma com um título significativo, que resume com eficiência o conteúdo da seção que segue. Por todo o livro, a vida de Verger aparece entremeada à sua obra. Os dados efetivamente biográficos, sobre a sua infância na França ou sua família, só aparecem de fato a partir da metade do livro, o que reforça a ideia de indistinção entre vida pessoal e vida laboral. Assim, a história de vida de Verger ganha um sentido subliminar que torna a leitura sobre a sua história mais densa; fica clara a ideia de que a busca pessoal de Verger pautava sua obra e vice-versa.

A indissociação entre vida e obra de Verger se reflete também em sua principal teoria (e a única, segundo Souty, sobre a qual reivindicou autoria): a dos orixás como arquétipos de personalidade. Souty defende que Verger tinha consciência de que foi levado a formular esta teoria por razões pessoais: como na África os orixás são ancestrais divinizados, e, portanto, presentes geneticamente em seus descendentes, como seria possível que um branco, sem essa herança genética, pudesse trazer consigo essa presença? Verger concluiu que os orixás têm uma dupla natureza, podendo ser tanto ancestrais divinizados quanto arquétipos mais gerais da personalidade humana. Assim, um filho de Xangô poderia ser tanto seu descendente direto (no caso africano) quanto ter uma personalidade condizente com a do orixá (no caso brasileiro) (:162). Assim, durante a feitura, a pessoa torna-se mais ela mesma, ainda que essa vontade não parta diretamente dela.

Mas essa não foi a única contribuição importante de Verger para a antropologia das religiôes de matriz africana: é de sua autoria também a teoria do verbo atuante, que identifica o poder performativo da linguagem no candomblé. Seus escritos sobre o transe e sobre a noção de pessoa africana também foram fundamentais para os estudos sobre as religióes de matriz africana, tendo papel fundamental em muitas das teorias de Bastide, de quem foi colaborador assíduo.

Durante todo o livro, podemos acompanhar o papel fundamental dos amigos na vida de Verger, e ter a dimensão da importância destes em sua “obra-vida” e vice-versa. Métraux e Bastide o estimulam a enveredar-se na escrita (:146), e foi no diálogo com eles, além de Leiris e Lydia Cabrera, que Verger formulou a maioria de suas ideias. Mas Verger também construiu inimizades: desentendeu-se com Herskowits, já que este considerava o desenvolvimento do candomblé baiano autônomo, enquanto Verger buscava conexóes e 
similaridades com a África (:220). E opôs-se publicamente a Juana Elbein dos Santos, a quem acusou de manipular dados para construir teorias "fechadas". Souty levanta a hipótese de que esta querela pode também ser vista como possível fruto de um parentesco simbólico “demasiadamente estreito" (:270), já que Elbein era casada com Mestre Didi, filho de Mãe Senhora, que havia iniciado Verger.

Já o parentesco consanguíneo de Verger só nos é apresentado a partir da metade do livro de Souty. Ali ficamos sabendo do sentimento de inadequação que o acompanhou por toda a sua infância e da gradual perda de todos os membros de sua família no período entre 1914 e 1932. Quando a sua mãe morre, em 1932, ele parte em uma viagem praticamente sem volta. Havia acabado de completar trinta anos, "sem diploma e nem emprego" (:240). Nesse mesmo ano, resolve que cometeria suicídio assim que completasse quarenta anos (plano posteriormente abandonado, como se vê). Quando chega o dia marcado, 4 de novembro de 1942, ele está em Cuzco, no Peru, e aparentemente se esquece de seu plano: "frustrei minha morte" (:249).

Porém, a quase morte marca o início de uma nova vida para Verger. De Cuzco, ele segue viagem pelos Andes até que, em 1946, chega a Salvador (seguindo uma dica que Bastide lhe dera) e permanece lá durante dois anos trabalhando como repórter fotográfico para a revista $O$ Cruzeiro. "Após quinze anos viajando pelo mundo, parece ter encontrado seu lugar” (:257). Segundo Souty, na Bahia Verger conseguia conviver com os negros em pé de igualdade, o que o levou a construir uma visão idealizada da cidade e, por conseguinte, do candomblé, visto por ele como forma de manutenção e de resgate da autoestima dos negros $(: 262)$.

Em 1946 Verger embarca para a África, e na volta desta viagem, em 1948, dá o seu primeiro bori com Mãe Senhora. Foi a partir da sua relação com o candomblé que Verger foi acolhido pela população negra de Salvador, e por causa deste acolhimento (de um branco europeu por uma religião de negros de origem africana) que ele desenvolveu a teoria da dupla característica dos orixás. Souty analisa o processo iniciático de Verger com base na teoria dos ritos de passagem de Van Gennep (separação, marginalização e agregação), alternando as fases de suas iniciaçóes com momentos de sua vida pessoal. Com isso, consegue mostrar como esses dois aspectos da vida de Verger são indissociáveis: trata-se, realmente, de uma "obra-vida". 
Posteriormente, já como oju obá do Ilê Axé Opô Afonjá, ele inicia-se como babalaô na regiáo de Ketu, e ganha o nome de Fatumbi, "um segundo eu mesmo" segundo palavras do próprio (:290). Em 1954 Verger lança o livro Dieux d'Afrique comparando imagens feitas no Brasil e na África, iniciando a sua atuação como mensageiro transatlântico (:113). Verger buscava, mais do que atestar que esta ou aquela tradição era real, estabelecer um elo entre as religiōes tradicionais negras na África e no Brasil. Com este fim, transportou da África para o Brasil (e também na direção inversa) objetos, histórias, documentos. Foi baseado nessa dimensão da relação África-Brasil que Verger elegeu o candomblé ketu (o "modelo cultural ioruba" - :181) como o legítimo representante desta tradição, o que terminou por gerar controvérsias tanto dentro do próprio candomblé quanto na academia. $\mathrm{Na}$ análise de Souty sobre a "tradição" africana no Brasil, ele mostra como Verger, ao mesmo tempo em que foi um dos artífices desta "invenção da tradição" (termo cunhado por Hobsbawn e apropriado por Beatriz Góis Dantas e Stefania Capone numa espécie de "denúncia" sobre a suposta influência de antropólogos e intelectuais nos terreiros de candomblé), também se interessou pelos modelos de sincretismo existentes no Brasil (:195), defendendo que o sincretismo entre o candomblé e o catolicismo seguia o modelo da “justaposição sem oposição” (:197). Como destaca Souty, com propriedade, "entre destacar a fidelidade e defender a 'pureza', a fronteira é tênue" (:181) e Verger foi criticado por ter priorizado o modelo iorubá em detrimento das tradiçôes fon e angola, e defendeu-se afirmando que o modelo de culto iorubá era mais facilmente adaptável para o Brasil, pelo fato de adorar também os elementos da natureza. Sobre isso, nos diz Souty que "para uma apreciação justa, é necessário colocar-se a meio caminho entre essas duas interpretaçóes e não superestimar a influência dos trabalhos universitários na construção dos modelos rituais e das tradiçôes religiosas" (:204).

O contraponto à visão sincrética do próprio Verger vem, segundo Souty, da sua participação na fundação do terreiro de Balbino Daniel de Souza, mais conhecido como Obarayi (:223). Ali, Verger leva a cabo sua visão do que seria um terreiro "tradicional” e busca, com isso, implementar elementos já extintos das religióes africanas para legitimar esse processo (:225). Aqui, Souty deixa clara a sua crítica a esse envolvimento de Verger com a criação do terreiro de Obarayi. Segundo ele, "podemos considerar que Verger participou tardiamente de certa ‘folclorização’ do culto” (:225). 
O livro de Souty segue, de alguma maneira, o estilo de Pierre Verger: ainda que sem alarde, em um estilo mais descritivo que teórico, Souty apresenta, perto do final do livro, uma teoria consistente sobre o segredo no candomblé (:327). Primeiramente, mostra-nos como Verger se relacionou com a questáo do segredo: apesar de ter se iniciado, como dizia, para ter acesso ao segredo (e de ter usado a iniciação como método de pesquisa), Verger nunca revelou a maioria das informaçóes a que teve acesso, na maior parte das vezes por iniciativa pessoal (:339). "Na obra etnográfica de Verger, há uma grande parte de silêncio" (:328). É curioso que uma obra tão profícua como a de Verger tenha sido erigida sobre tal dialética, mas, como nos lembra Souty, “o pilar sobre o qual repousa o saber oral iorubá é também o depositário do segredo: aquele que conserva e transmite é também aquele que esconde” (:334). Foi em cima dessa dupla reação que Verger construiu a sua obra: “o silêncio foi bastante relativo. Sem (...) trair a lei do segredo, ele mostrou, escreveu e disse muito" (:340).

Mas Souty vai além da relação de Verger com o segredo: segundo ele, o segredo é parte da experiência do candomblé justamente porque se relaciona a diversos aspectos de sua prática. Sua presença tanto funciona, segundo Souty, como elemento de coesão do grupo, quanto faz parte do processo de aprendizado. O candomblé estaria, podemos dizer, impregnado pelo segredo. "O segredo participa diretamente da dinâmica de comunicação e redistribuição da energia sagrada axé” (:349). Assim como o axé é o elemento fundamental da dinâmica de funcionamento de um terreiro de candomblé, Souty defende que o segredo, estando diretamente ligado a ele, seria também parte desta organização, ao mesmo tempo como elemento diferenciador (entre os que sabem mais e menos) e de uniáo (pois une o grupo em torno de sua proteçáo) (:347). O segredo, além disso, aparece em camadas (:348): Souty cita como exemplo o famoso testamento de Marcelina Obatossi, que, segundo ele, “é revelador justamente pelo que náo diz" (:351).

O tema da metodologia é retomado ao fim do livro, quando a análise do método de pesquisa de Verger (que Souty chama "antropologia iniciática" - :395) serve também como mote para observaçóes mais gerais sobre o método etnográfico, especialmente valiosas para pesquisadores que trabalham com o tema das religióes de matriz africana que se deparam com a questão da iniciação em seus locais de pesquisa. Souty chega a sugerir que se pense a relação entre etnógrafo ${ }^{1}$ e o que ele denomina "objeto de estudo" nos moldes do princípio de corte de Roger Bastide (que defendia que os participantes das religióes de matriz africana 
abandonavam a sua identidade cotidiana quando entravam nos terreiros, assumindo uma posição de poder dentro daquela estrutura - poder que lhes era negado no dia a dia). Ou seja, que o pesquisador possa participar do grupo sem, no entanto, assumir uma postura religiosa (:402). Porém, logo depois Souty afirma que, de lá para cá, “a iniciação do pesquisador tornou-se assim uma coisa quase banal" (:404), "defendida e reivindicada como um princípio metodológico que legitima a observação participante" (:403), chamando a atenção, porém, para os riscos envolvidos neste processo (:411).

Se o candomblé é, como vimos, uma religião do ato, do fazer, poderíamos dizer que a antropologia de Verger é uma antropologia do fazer (:418). Souty defende que a obra de Verger representa uma "revolução copernicana na antropologia" (:418), pois, ainda que sem alarde, representou "uma crítica ao etnocentrismo ocidental, portanto ao logocentrismo e ao escriptocentrismo" (:419). Verger “quis encontrar o outro, e não objetivá-lo" (:420), nos diz Souty, e "teve o privilégio de viver várias vidas, de pertencer a vários mundos numa única vida" (:422). E, ao chegar ao fim do livro, somos obrigados a concordar com ele.

\section{Notas}

$1 \mathrm{O}$ autor alterna o tratamento dado a Verger: em alguns momentos o chama de etnógrafo, em outros de etnólogo. Sobre isso, convém lembrar que somente no Brasil o termo etnologia se refere especificamente à etnologia indígena. 